\title{
Reply to the Comment by llhan et al. on Our Paper Entitled 'Effect of Macular Ischemia on Intravitreal Ranibizumab Treatment for Diabetic Macular Edema'
}

\author{
Irini Chatzirallia Maria Douvali $^{\mathrm{b}}$ Panagiotis Theodossiadis ${ }^{\mathrm{b}}$ Alexandros A. Rouvas ${ }^{\mathrm{b}}$ \\ a 2 nd Department of Ophthalmology, Ophthalmiatreion Athinon Eye Hospital, and ${ }^{\mathrm{b}}$ 2nd Department of \\ Ophthalmology, Attikon Hospital, University of Athens, Medical School of Athens, Athens, Greece
}

\section{Dear Editor}

We would like to thank Ilhan et al. [1] for their valuable remark. Our results demonstrated that macular ischemia may have a negative impact on functional outcome at the 6-month follow-up after intravitreal ranibizumab treatment in patients with diabetic macular edema (DME), while an anatomical improvement was noticed, as indicated by the decrease in central retinal thickness [2]. This finding is in line with Chung et al. [3] who reported that, after a short-term follow-up, macular ischemia is a negative prognostic factor of visual outcome in patients with DME treated with intravitreal bevacizumab. Both studies suggested that macular ischemia and subsequent chronic hypoxia cause irreversible damage to photoreceptors, resulting in poor visual outcome despite the structural restoration and resolution of DME after the use of anti-vascular endothelial growth factor agents $[2,3]$. Therefore, the principal message of our study was not to avoid intravitreal anti-vascular endothelial growth factor agents in patients with ischemic DME, but to use them with caution, taking into account that the final visual outcome may not be promising. In fact, the decision to treat should be made in each patient in- dividually and based on fluorescein angiogram findings rather than optical coherence tomography measurements [4]. Of note, the recent results of the RESTORE extension study, which also included patients with ischemia, showed that intravitreal ranibizumab is effective as regards visual acuity and central retinal thickness in patients with DME [5].

On the other hand, DME duration may be a potential prognostic factor for the posttreatment visual outcome in patients with DME, in the sense that the longer DME lasts, the more long-lasting damage it can cause to photoreceptors [6]. In our study, macular ischemia was the main factor examined, and we did not include DME duration in the analysis, since this information was not available for some patients. Furthermore, DME duration is difficult to be determined objectively, as patients could have had the symptom for some time without having realized or they may not visit a doctor promptly. In any case, further prospective studies are needed to determine the effect of DME duration, as good as it can be assumed at the time of DME diagnosis, on the prediction of posttreatment visual outcome in patients with DME.

\section{References}

1 Ilhan A, Tas A, Yolcu U, Gundogan FC: Comment on the paper by Douvali et al. entitled ' $\mathrm{Ef}$ fect of macular ischemia on intravitreal ranibizumab treatment for diabetic macular edema'. Ophthalmologica DOI: 10.1159/00369891.

2 Douvali M, Chatziralli IP, Theodossiadis PG, Chatzistefanou KI, Giannakaki E, Rouvas AA: Effect of macular ischemia on intravitreal ranibizumab treatment for diabetic macular edema. Ophthalmologica 2014;232:136-143.

3 Chung EJ, Roh MI, Kwon OW, Koh HJ: Effects of macular ischemia on the outcome of intravitreal bevacizumab therapy for diabetic macular edema. Retina 2008;28:957-963.

4 Manousaridis K, Talks J: Macular ischaemia: a contraindication for anti-VEGF treatment in retinal vascular disease? $\mathrm{Br} \mathrm{J}$ Ophthalmol 2012;96:179-184.

-5 Schmidt-Erfurth U, Lang GE, Holz FG, Schlingemann RO, Lanzetta $\mathrm{P}$, Massin $\mathrm{P}$, Gerstner O, Bouazza AS, Shen H, Osborne A, Mitchell P; RESTORE Extension Study Group: Three-year outcomes of individualized ranibizumab treatment in patients with diabetic macular edema: the RESTORE extension study. Ophthalmology 2014;121:1045-1053.

6 Larsson J, Zhu M, Sutter F, Gillies MC: Relation between reduction of foveal thickness and visual acuity in diabetic macular edema treated with intravitreal triamcinolone. Am J Ophthalmol 2005;139:802-806.

\section{KARGER 125\%}

(c) 2014 S. Karger AG, Base

$0030-3755 / 14 / 2332-0116 \$ 39.50 / 0$
Alexandros A. Rouvas, MD, PhD

2nd Department of Ophthalmology, Attikon University Hospital

1, Rimini Street, Haidari

GR-12462 Athens (Greece)

E-Mail alexander.rouvas@gmail.com 